\title{
Shear and Flexural Behavior of Reinforced Concrete Deep Beams Strengthened with CFRP Composites
}

\author{
Hana' Al-Ghanim ${ }^{1}$, Aya Al-Asi ${ }^{1}$, Mu'tasim Abdel-Jaber ${ }^{1} \&$ Maha Alqam $^{1}$ \\ ${ }^{1}$ Civil Engineering Department, School of Engineering the University of Jordan, Amman, Jordan \\ Correspondence: Mu'tasim Abdel-Jaber, Civil Engineering Department, The University of Jordan, Amman \\ 11942 Jordan. E-mail: m.abduljaber@ju.edu.jo
}

Received: September 14, 2017

Accepted: September 21, 2017 Online Published: September 28, 2017

doi:10.5539/mas.v11n10p110

URL: https://doi.org/10.5539/mas.v11n10p110

The research is financed by the Deanship of Scientist Research at The University of Jordan.

\begin{abstract}
The current research studies the shear and flexural behavior of reinforced concrete (RC) deep beams strengthened with externally bonded carbon fiber-reinforced polymers (CFRP). Using two types of CFRP composites including sheets and laminates, different configurations for shear and flexural strengthening of deep beams were experimentally investigated. In total, twenty specimens of deep beams with cross-sectional dimensions of $190 \mathrm{~mm}$ width, $400 \mathrm{~mm}$ depth and an overall length of $1900 \mathrm{~mm}$ were casted and tested to failure. Concerning the cracks' formation, failure's modes, ultimate strength and overall stiffness, the performance of the strengthened beams compared to the control beams were evaluated. From the test results, the effectiveness of CFRP technique on enhancing both the shear and flexural capacity of deep beams is verified; however, the efficiency differs variedly depending on the material and the strengthening scheme. Regarding the shear strengthening, using the continuous wrap of two sheets records the highest increase in the ultimate strength with a value exceeds $86 \%$ compared only to $36 \%$ with the inclined laminates. On the other hand, an enhancement of about $51 \%$ is achieved through the flexural strengthening with two layers of sheets and $26 \%$ when the laminates are used; both are accompanied by a divergent in the failure mode from flexure to shear.
\end{abstract}

Keywords: CFRP, deep beams, flexural strengthening, laminates, shear strengthening, sheets

\section{Introduction}

Reinforced concrete (RC) deep beams, generally, are structural elements with short shear spans. In such members, shear is the dominative mode for failures and the shear strength of deep beams is; therefore, a major consideration in their design (Yang et al., 2003, Zhang et al., 2004, Nawy, 2009). In practice, RC deep beams have many useful structural applications in high-rise buildings, offshore structures and in foundation systems (Islam et al., 2005, Lee et al., 2011). Commonly, RC deep beams are used as load transferring structural elements such as transfer girders, supporting the load from one or more columns and transferring it laterally to other columns (Wight \& MacGregor, 2012).

However, many existing RC structures were constructed before the introduction of modern design codes. Moreover, a large number of current civil infrastructure, such as highway bridges, are rated as structurally deficient caused by a significant increase in traffic volume, inadequate maintenance, inappropriate construction and environmental deterioration (Lee et al., 2011, Park \& Abouatah, 2009). On this basis, the deep beams in many of these structural applications are susceptible to failure, and thus need to be strengthened or retrofitted. Compared to flexural failure, shear failure in deep beams commonly controls, particularly when the shear reinforcements are corroded or in the case of increasing the flexural strength due to flexural strengthening. Nevertheless, flexural failure can also occur in one of two modes when insufficient flexural reinforcements are used or the bars are severely corroded, causing an excessive yielding of the tensile reinforcements or failure of the bar's anchorage. In such cases, the shear and flexural resistance should be improved to prevent suddenly catastrophic failures (National Cooperative Highway Research Program's Report [NCHRP Report 678], 2011).

One possible technique for improving the total capacity of RC beams is the external attachment of carbon fiber-reinforced polymer (CFRP) composites to the surfaces of beams using epoxy adhesives. Compared to 
conventional techniques in structural strengthening, the use of CFRP composites has grown popularly and become a widely accepted technique. Their significant high tensile strength resulted in making them more efficient than other strengthening materials. Because of their lightweight and exceptional ease of installation, CFRP materials can also be attached to the most irregular surfaces (Belarbi \& Acun, 2013).

In terms of shear and flexural strengthening of RC slender beams using different types of CFRP materials along with various amounts and configurations, a considerable number of research studies have been carried out in recent years, all of which have provided valuable results with respect to the significant enhancement of both shear and flexural resistance and modes of failure (Khalifa \& Nanni, 2002, Hsu et al., 2003, Adhikary \& Mutsuyoshi, 2004, Lamanna et al., 2004, Al-Amery \& Al-Mahaidi, 2006, Abdel-Jaber et al., 2007, Esfahania et al., 2007, Jayaprakash et al., 2008, Siddiqui, 2009, Ceroni 2010, Mofidi \& Challal, 2011, Sobuz et al., 2011, Attari et al., 2012, Al-Tersawy, 2013, Baggio et al., 2014). However, a comprehensive review of previous works revealed that most of these experimental studies have investigated primarily the shear or flexural strengthening of slender beams and involved specimens of reduced sizes with a depth of less than $300 \mathrm{~mm}$ (Park \& Abouatah, 2009, Bousselham \& Chaallal, 2006, Godat \& Chaallal, 2013).

Up to date, the behavior of RC deep beams strengthened with CFRP composites has received little consideration in the literature and the experimental investigations conducted have been found to be very limited (Zhang et al., 2004, Islam et al., 2005, Lee et al., 2011). Therefore, further experimental investigations are still needed to evaluate the performance of the strengthened deep beams under various strengthening schemes, and hence better understanding of shear and flexural resistance mechanisms associated with the use of CFRP systems could be achieved (NCHRP Report 678, 2011).

Nevertheless, one of the experimental investigations conducted in this field showed a substantial increase in the shear strength of rectangular deep beams due to the use of externally bonded CFRP systems (Zhang et al., 2004). The values of increase in the ultimate strength ranged between $45 \%$ and $52 \%$ for the beams strengthened with CFRP fabrics, whereas by using CFRP laminates, these values reached to $42 \%$ and $66 \%$ depending on the arrangement of laminates. A similar study explored the potential use of three various types of CFRP systems for shear strengthening of rectangular deep beams (Islam et al., 2005). In general, although the use of CFRP grids in normal orientation was adopted as the most effective system concerning the amount of material consumed, other systems of CFRP wrap and strips were also found to be equally effective with a total enhancement reached to about $43 \%$. Another experimental research was carried out to investigate the behavior of T-section deep beams retrofitted in shear by CFRP sheets (Lee et al., 2011). From the results, it was concluded that the length of sheets and the different combinations of fibers' orientation had a considerable influence on the shear performance of the strengthened beams such that $10 \%$ to $66 \%$ increases in the ultimate strength were observed.

The main objective of the current study is to define the contribution of the externally bonded CFRP composites on enhancing the shear and flexural capacity of RC deep beams concerning the cracks' pattern, ultimate strength, modes of failure and the overall stiffness. Other principle objectives can be listed as follows:

- Evaluate the effectiveness of two forms of CFRP composites; these are sheets and laminates.

- Evaluate the effectiveness of eight different configurations for shear and flexural strengthening through investigating the influence of principle parameters such as fibers' orientation, number of layers of sheets and width of laminates.

- Determine the best configurations for shear and flexural strengthening of RC deep beams considering the economic aspect.

\section{Experimental Program}

A series of experimental tests were performed on two main groups of deep beams with a total of twenty beams. The first group, Group (A), was set to investigate the shear behavior, while in the second group, Group (B), the focus was on the flexural performance. Each main group was then subdivided into three groups: group I, group II and group III, such that the first group consisted of two control beams, while the remaining two groups comprised eight strengthened beams. Two identical beams were constructed for each scheme of strengthening in order to ensure more reliable and valid results. Table 1 summarizes the details of test specimens as well as the strengthening schemes.

\subsection{Test Specimens}

Twenty identical specimens of deep beams with cross-sectional dimensions of $190 \mathrm{~mm}$ width, $400 \mathrm{~mm}$ depth and an overall length of $1900 \mathrm{~mm}$ were cast and tested. The beams were designed according to the provisions of the Strut-and-Tie Model as provided by the American Concrete Institute's Code (ACI 318M-14). In general, the 
beams of Group (A) were designed to fail due to shear rather than in flexure. Accordingly, each beam was mainly reinforced to resist the resultant bending moment using six $16 \mathrm{~mm}$ diameter bars arranged in two layers at the bottom, while the shear reinforcements were not provided. As a result, the beam was predicted to fail in shear prior to yielding of tensile reinforcement or compressive crushing of concrete in both cases; before and after strengthening. However, three stirrups were used in the mid-span and near the two supports to hold the longitudinal bars in position and to avoid any possibility of local failure at the supports. In contrast, all the beams of Group (B) were planned to fail in flexure instead of shear following the minimum required reinforcement ratio with two $14 \mathrm{~mm}$ diameter bars placed in one layer at the bottom, whereas the shear reinforcements were extensively provided using transverse and longitudinal stirrups with a diameter of $8 \mathrm{~mm}$ and center to center spacing of $80 \mathrm{~mm}$. Reinforcement details of beams' specimens within Groups (A) and (B) are illustrated in Figure 1.

The beams were constructed using a ready mix concrete with a normal cylinder compressive strength of $30 \mathrm{MPa}$. For the longitudinal reinforcements, high yield strength deformed bars of grade $60 \mathrm{ksi}$ (420 MPa) were used, whereas the stirrups were fabricated using plain steel bars of grade $40 \mathrm{ksi}(280 \mathrm{MPa})$.

Table 1. Details of test specimens

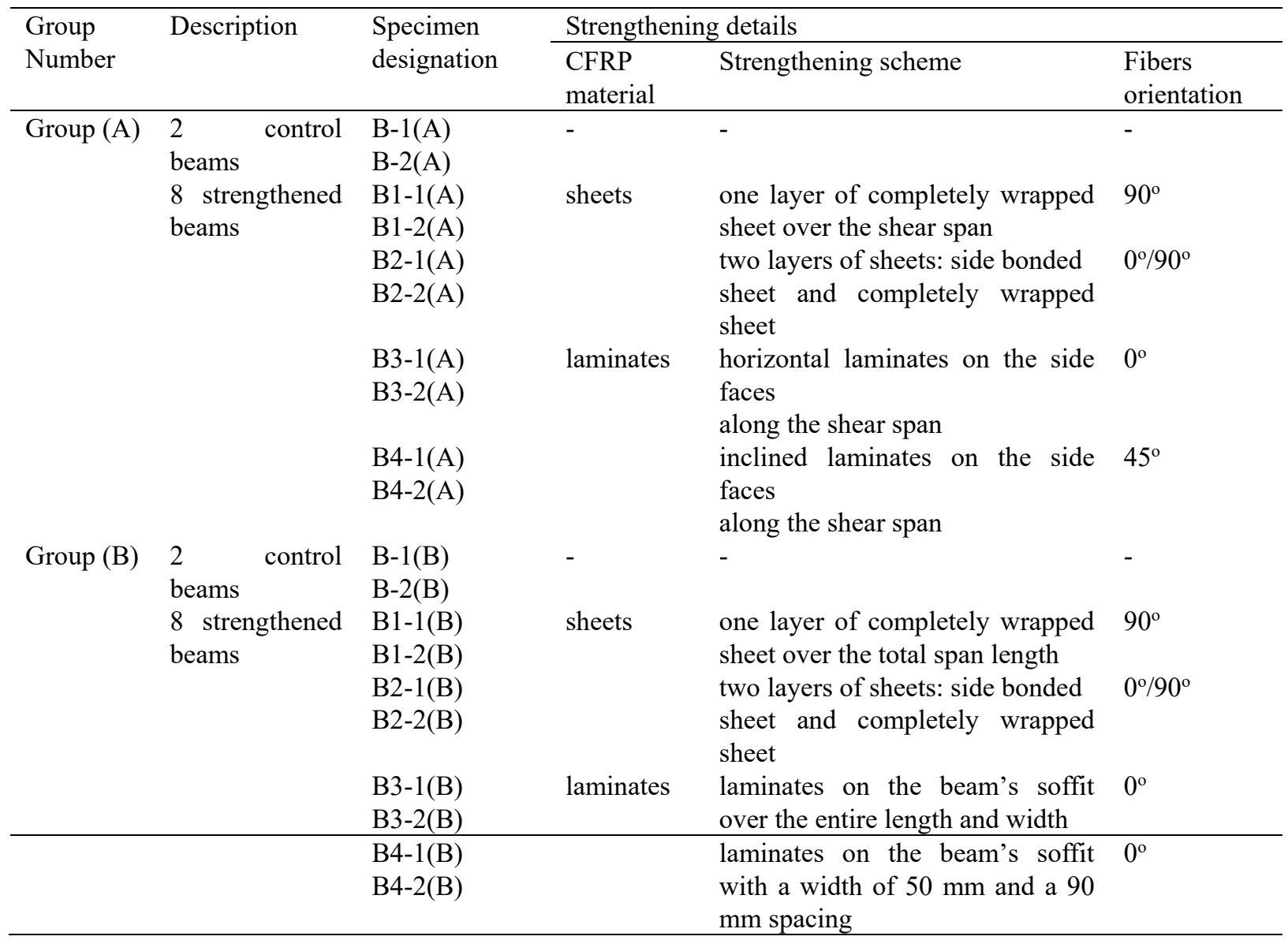

\subsection{CFRP Materials and Strengthening Schemes}

Through this experimental investigation, two forms of CFRP composites were used; these are sheets and laminates with the typical properties listed in Table 2. It should be noted that in CFRP technique, the attainment depends mostly on the mechanical properties and the performance of the adhesive used for bonding the CFRP materials to the beam's surfaces. The adhesive system used in this work consisted of two components of epoxy resin; a resin and a hardener. 


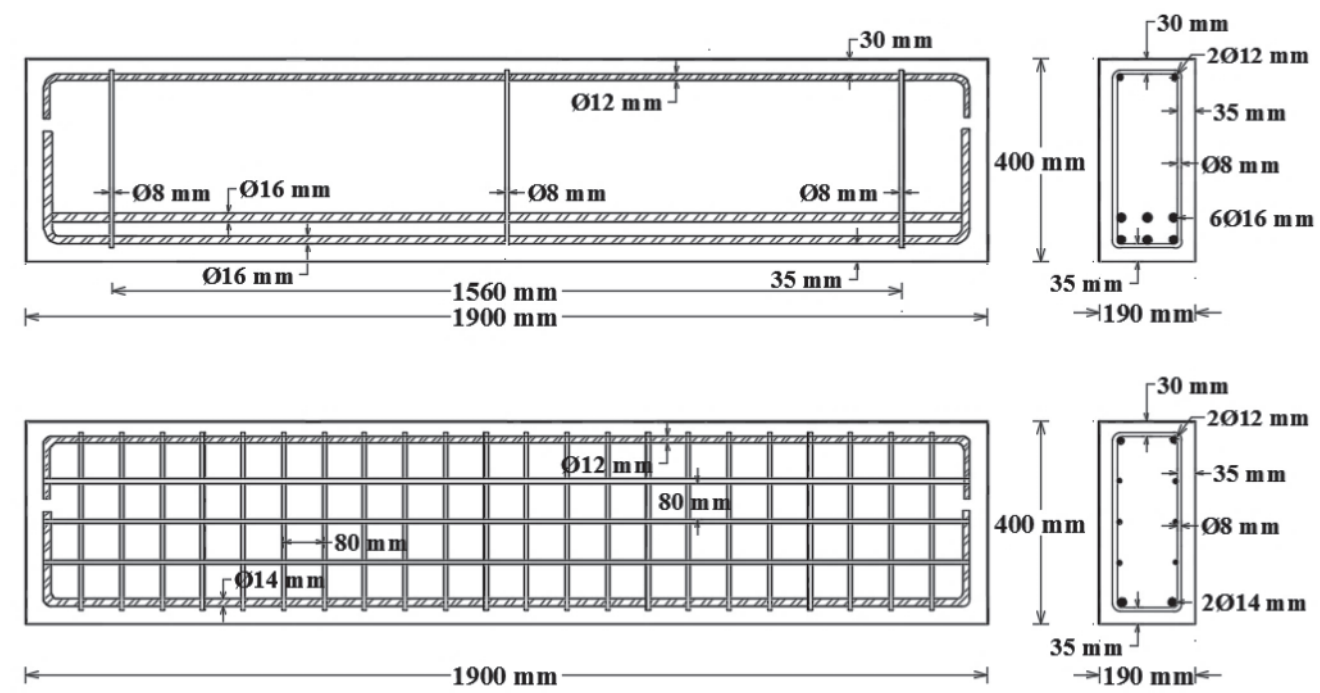

Figure 1. Reinforcement details of beam's specimens within Group (A) and Group (B).

Table 2. Typical properties of CFRP materials.

\begin{tabular}{|c|c|c|c|c|}
\hline CFRP material & $\begin{array}{l}\text { Tensile strength } \\
(\mathrm{MPa})\end{array}$ & Modulus of elasticity (GPa) & $\begin{array}{l}\text { Thickness } \\
(\mathrm{mm})\end{array}$ & $\begin{array}{l}\text { Width } \\
(\mathrm{mm})\end{array}$ \\
\hline MBrace FIBRE CF 230/4900 & 4900 & 230 & 0.17 & 500 \\
\hline $\begin{array}{lll}\text { MBrace } & \text { LAMINATE } & \text { CF } \\
165 / 3000 & & \end{array}$ & $>3000$ & $>165$ & 1.2 & 100 \\
\hline
\end{tabular}

For the strengthened beams of Group (A), the four beams of group II were strengthened in shear using the CFRP sheets such that two beams were strengthened with completely wrapped sheet applied vertically along the shear spans, whereas an additional sheet was horizontally bonded only to the side faces for the other two beams. The remaining four beams of group III were enhanced in shear with two different arrangements of CFRP laminates such that the first configuration was built by distributing the laminates horizontally over the total depth of the beam, while for the other scheme, the laminates were attached along the shear spans at an angle of $45 \mathrm{o}$ with respect to the beam's longitudinal axis. Figure 2 shows the strengthening schemes of beams in Group (A).

In a similar manner, the eight strengthened beams of Group (B) were enhanced in flexure following four different arrangements. For the four beams of group II, CFRP sheets were continuously applied over the entire beams using one layer of sheets in the first two beams with an additional layer horizontally placed on the side faces for the reaming two beams. In the beams of group III, the soffits of the beams were strengthened using the CFRP laminates in a way that the laminates were placed covering the total width of the beam along the entire span length in the first scheme, while the second configuration was built using a $50 \mathrm{~mm}$ width of laminates and a clear spacing of $90 \mathrm{~mm}$ along the entire span length. Figure 3 illustrates the four strengthening schemes of beams in Group (B).

As a first step in beams' strengthening, the concrete's surface was subjected to smoothing using suitable sandpapers followed by washing and drying with water and an air blower to remove any loose materials, laitance and dust. Once the beam's surface was prepared to a desirable stage, the epoxy resin was provided according to the instructions given by the manufacturer. Both components of epoxy resin were uniformly mixed and immediately applied across the whole surface with an approximate thickness of $3 \mathrm{~mm}$. The CFRP laminates were then placed over the epoxy with a moderate pressure of a hammer to squeeze the epoxy and remove any entrapped air bubbles. A further layer of epoxy was directly spread over the surface of the laminates, and thus assuring a complete coverage and a good bond. The same procedure was performed in attaching the first layer of CFRP sheets and repeated for bonding the second layer with applying an additional coat of epoxy after attaching all the layers to ensure that the fibers were completely saturated in epoxy. The strengthened beams were kept at room temperature for a minimum of seven days before testing. 


\subsection{Experimental Setup and Procedure}

The experimental tests were applied at the Structural Laboratory of The University of Jordan. All the specimens were tested in flexure as simply supported deep beams under two symmetrically loading points. Each concentrated load was applied at a distance of $400 \mathrm{~mm}$ from the center of the nearer support, keeping the shear span to depth ratio at 1.19 for the beam specimens in Group (A) and 1.11 for the tested beams of Group (B). A hydraulic jack with a determined capacity of $700 \mathrm{kN}$ was used to produce one concentrated load and then two concentrated loads were generated and transferred into the top of the tested beams through a properly transferrable system.

The same procedure was performed in testing all the beams' specimens. Each beam was placed over the supports, centered and leveled in its designated position under the hydraulic jack. Once the beam was set, the concentrated load was applied at a constant rate of loading up to the beam's failure. During loading, the vertical deflection at the mid-span as well as the cracks' formation and their propagation were recorded and monitored. For this purpose, the dial gauge was set and adjusted beneath the center of the beam to measure the beam's deflection. The recording process was taken at reasonable increments of loading and continued until the failure occurred.

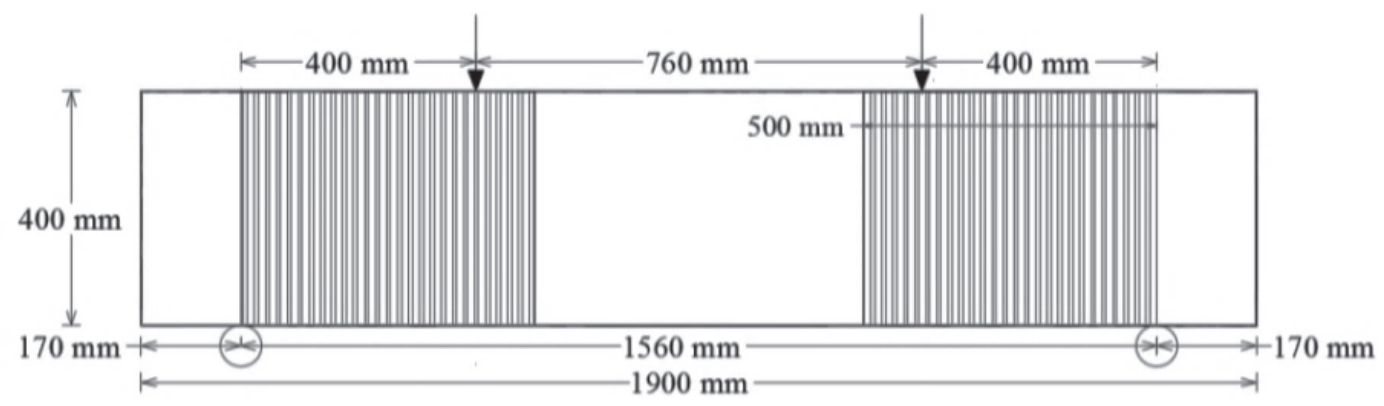

B1-1(A),B1-2(A)

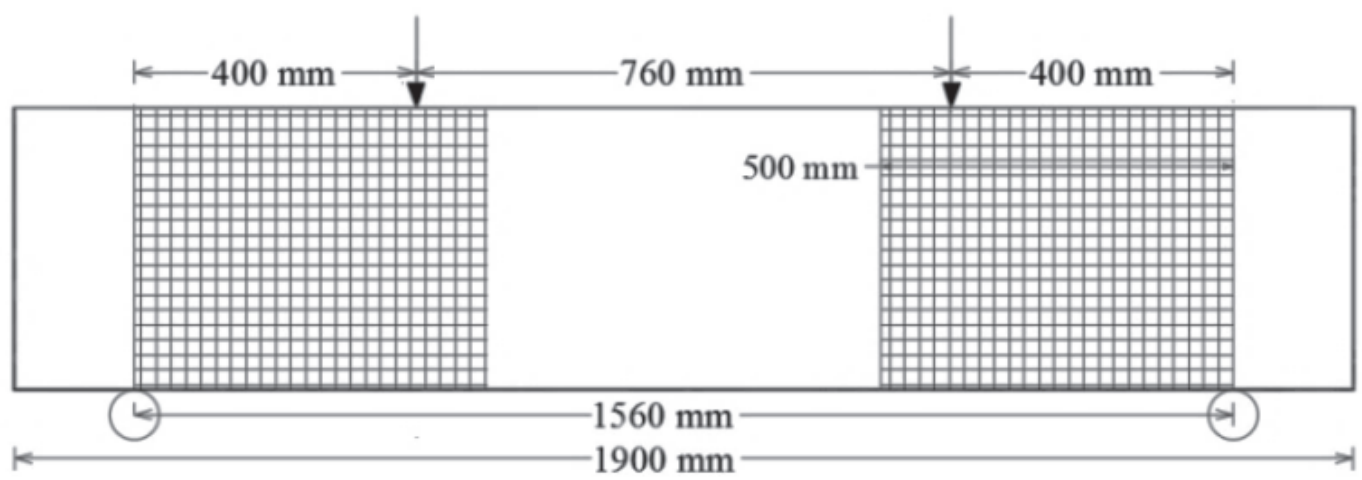

B2-1(A),B2-2(A)

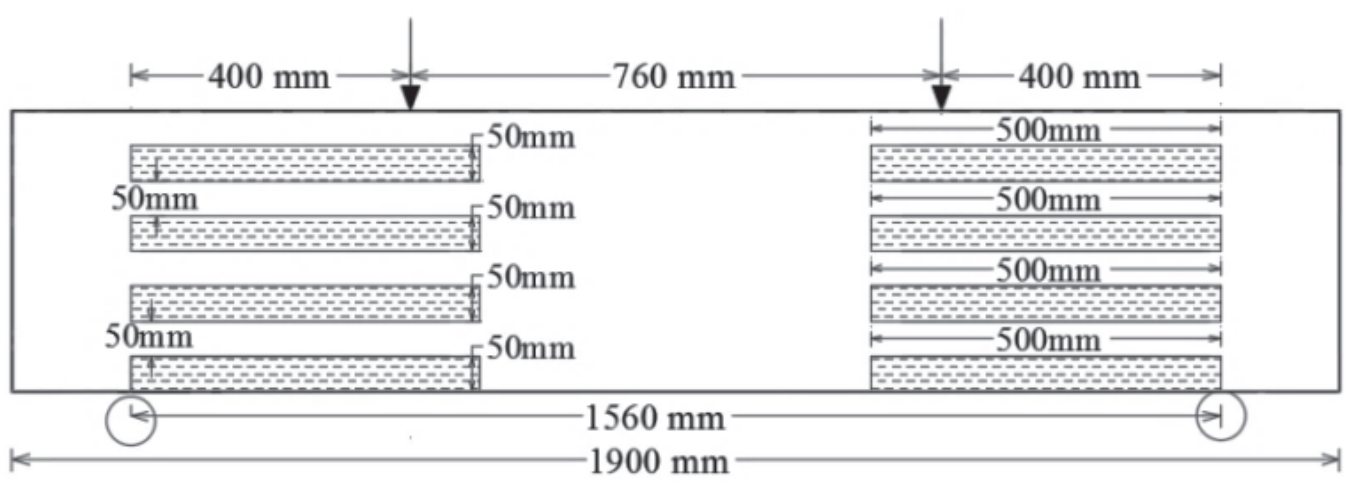

B3-1(A),B3-2(A) 


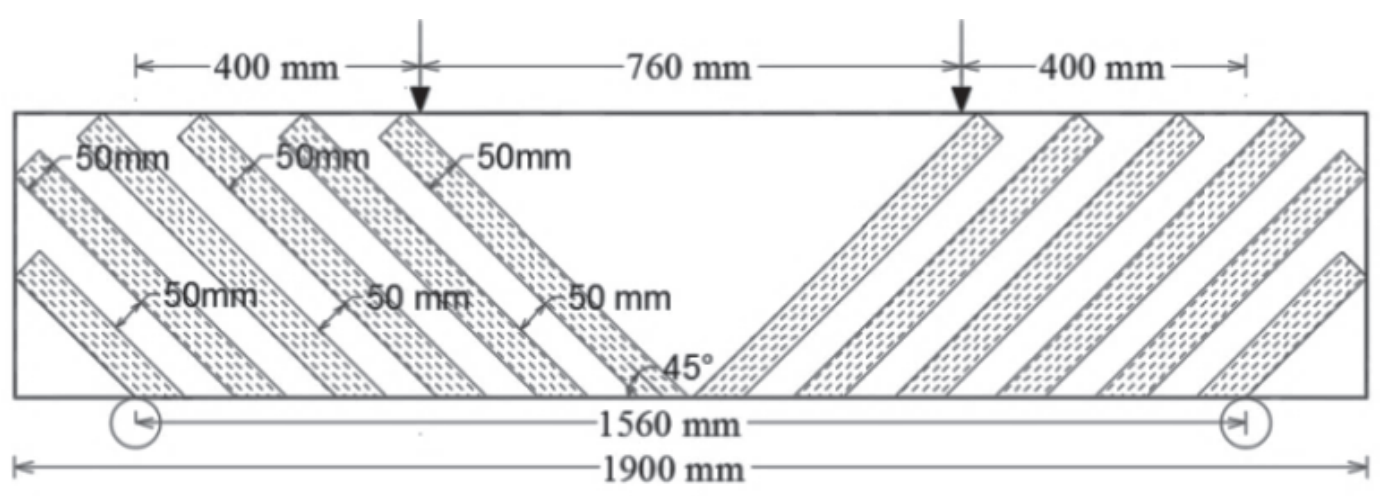

\section{B4-1(A),B4-2(A)}

Figure 2. Shear strengthening schemes of Group (A).

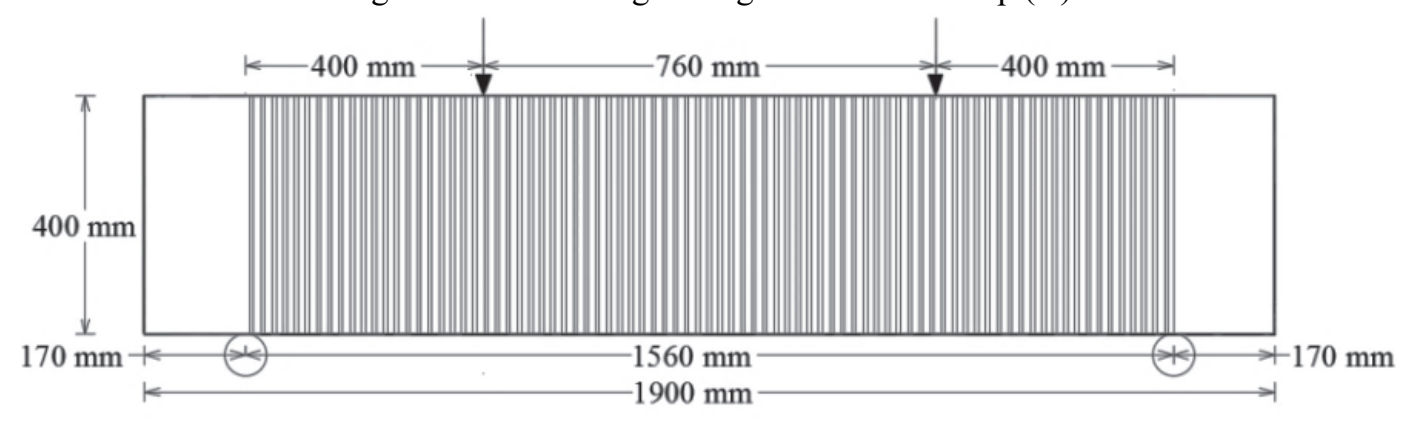

B1-2(B),B1-2(B)

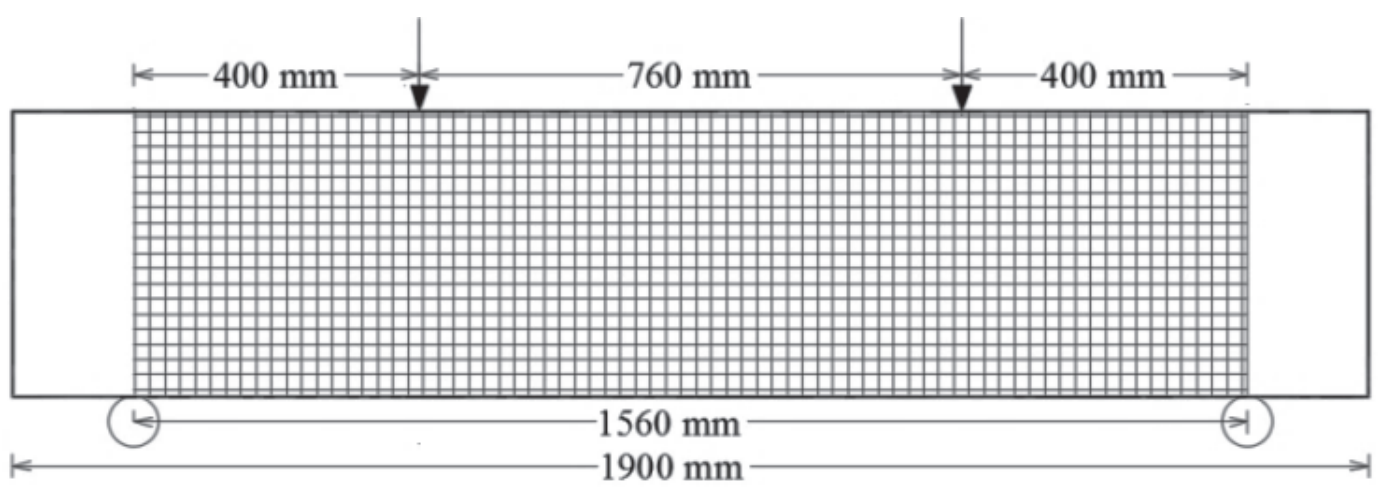

B2-1(B),B2-2(B)

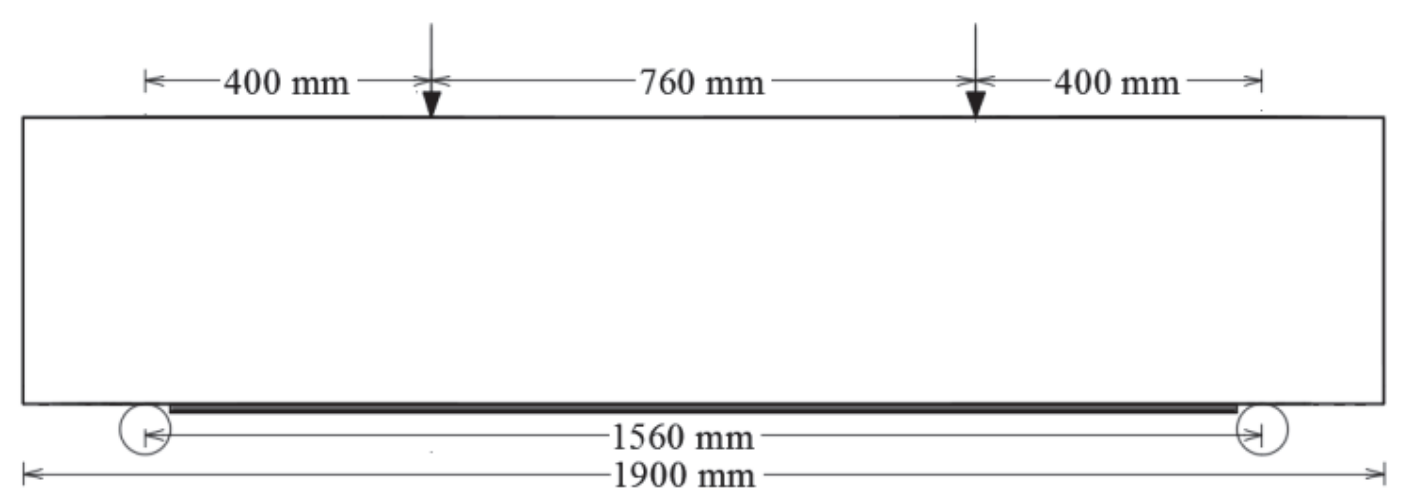

B3-1(B),B3-2(B),B4-1(B),B4-2(B) 


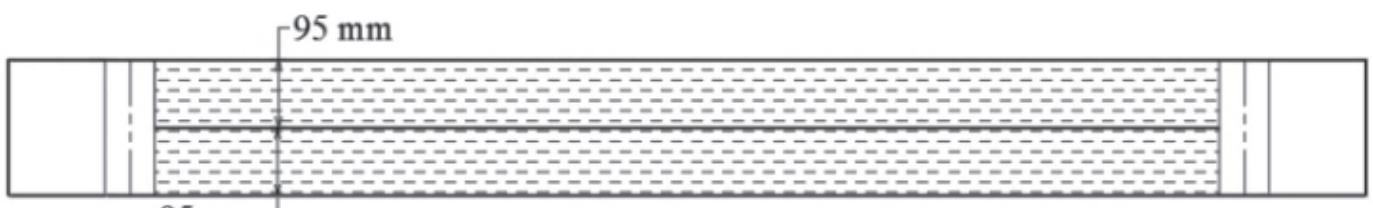

$95 \mathrm{~mm}$

Bottom view:B3-1(B),B3-2(B)

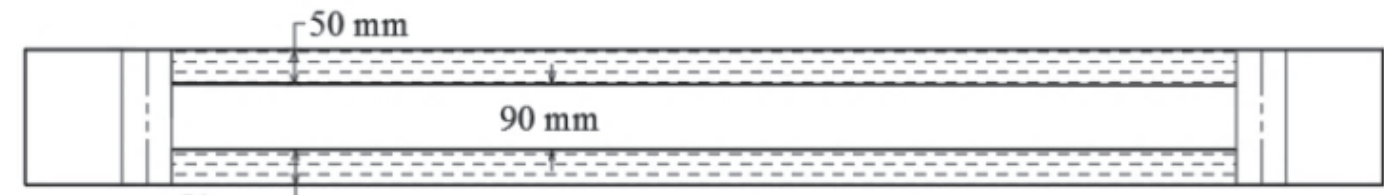

$50 \mathrm{~mm}$ Bottom view:B4-1(B),B4-2(B)

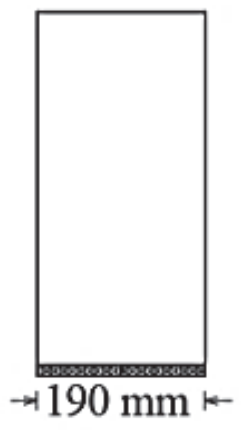

Side view:B3-1(B),B3-2(B)

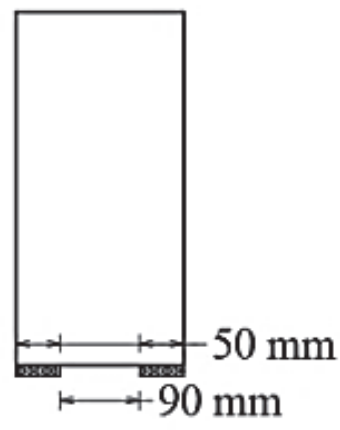

Side view:B4-1(B),B4-2(B)

Figure 3. Flexural strengthening schemes of Group (B)

\section{Results and Discussion}

\subsection{Cracks Development and Failure Modes}

\subsubsection{Beams of Group (A)}

The two control beams of Group (A) exhibited a similar sequence of cracks' development. Few hairline flexural carracks were initially observed at the mid-span of the beams. Diagonal shear cracks began to form shortly afterward in the region of the beams' shear spans. Simultaneously, the main diagonal crack; that is the critical crack that caused the failure, appeared and then propagated toward the loading point along increasing the applied loads. Once this crack fully developed between the support and the loading point, widening of the existing cracks was obviously noticed until the failure occurred.

For the four strengthened beams of group $I I$, in which CFRP sheets were used, it was not possible to observe the formation of the diagonal shear cracks on the side faces of the beams due to the continuous wrap of CFRP sheets, except during the final stages of loading when the main diagonal crack suddenly appeared through the external epoxy that coated the sheets. At this level, the load already reached more than $95 \%$ of the ultimate strength of the strengthened beams. In a similar manner, for the two beams of group $I I I$, which strengthened with the inclined CFRP laminates, the appearance of this crack occurred at a load level corresponding to about $92 \%$ of the ultimate strength. Nevertheless, the formation of the flexural cracks at the mid-span could be noticed such that the cracks' pattern formed was almost identical to that in the control beams. However, the two control beams were more extensively cracked than the strengthened beams, indicating the noticeable effect of using the CFRP materials on the cracks' propagation. Additionally, all the strengthened beams either with CFRP sheets or laminates showed a delayed formation of the critical crack, and hence confirming the influence of CFRP materials on the shear strength of deep beams.

The failure mode of the two control beams within group I was sudden and brittle in nature. The two beams failed suddenly in shear through the splitting of the concrete along the critical crack, followed directly by crushing of the concrete under the loading point. Within group $I I$, two different modes of shear failure were identified; these are partial delamination and rapid rupture of CFRP sheets; however, in the two cases, the failure was 
accompanied by crushing of the concrete around the support's region. It should be mentioned here that one of the two beams strengthened with two sheets, B2-1(A), did not fail and any supplementary increase in the applied load was no longer possible; since the hydraulic jack was attained to its maximum capacity of $700 \mathrm{kN}$. On the other hand, the four strengthened beams of group III showed one mode of shear failure due to the splitting of the concrete along the critical crack, associated with partial delamination of laminates as a result of shear. None of the beams in group III failed due to a premature debonding, delamination or rupture of CFRP laminates. Figure 4 displays the final failure pattern of the tested beams within Group (A).

\subsubsection{Beams of Group (B)}

For the two control beams of Group (B), flexural cracks initially appeared in the mid-span region between the two loading points such that all these cracks formed vertically, starting from the soffit of the beam, then continued to develop and elongate toward the mid-height of the beams along increasing the applied loads. Next, diagonal shear cracks began to form in the beam's shear spans, followed by the appearance of the main diagonal crack. The propagation of the flexural cracks continued and the existing ones kept on lengthening and widening until the failure.

For the four strengthened beams of group $I I$, it was difficult to observe the formation of both shear and flexural cracks; since the CFRP sheets covered the entire beams, except the cracks appeared through the external epoxy. Nevertheless, the final cracks' pattern formed was approximately similar to that of the control beams. For the strengthened beams of group $I I I$, in which the laminates were attached to the beams' soffit, a similar sequence of cracks' development was noted, forming a final pattern almost identical to that in the control beams. However, the two control beams were more extensively cracked, demonstrating the noticeable effect of using the CFRP materials on the cracks' formation. In addition, the rate of propagation of both the flexural and shear cracks was generally slower in the strengthened beams than that of the control beams.

In contrast to the failure mode of the control beams in Group (A), the failure mode of the two control beams within Group (B) was ductile in nature, as it was expected. The two beams failed in flexure through the rapid increase in the deflection's readings, indicating the excessive yielding of the tensile reinforcements, along with the obvious widening of the flexural cracks at the mid-span. Within group $I I$, the two different modes of shear

and flexure were recognized. The two beams strengthened with one layer of sheets failed in flexure as the deflection's reading was rapidly increased prior to the crushing of the concrete near the support, whereas the two beams strengthened with two layers failed in shear, causing the partial delamination of CFRP sheets near the support. On the other hand, all the four strengthened beams of group III failed in shear through diagonal splitting failure. It is worth mentioning that for the four beams of group III, partial debonding of laminates was observed prior to failure. Figure 5 displays the final failure pattern of the tested beams of Group (B).
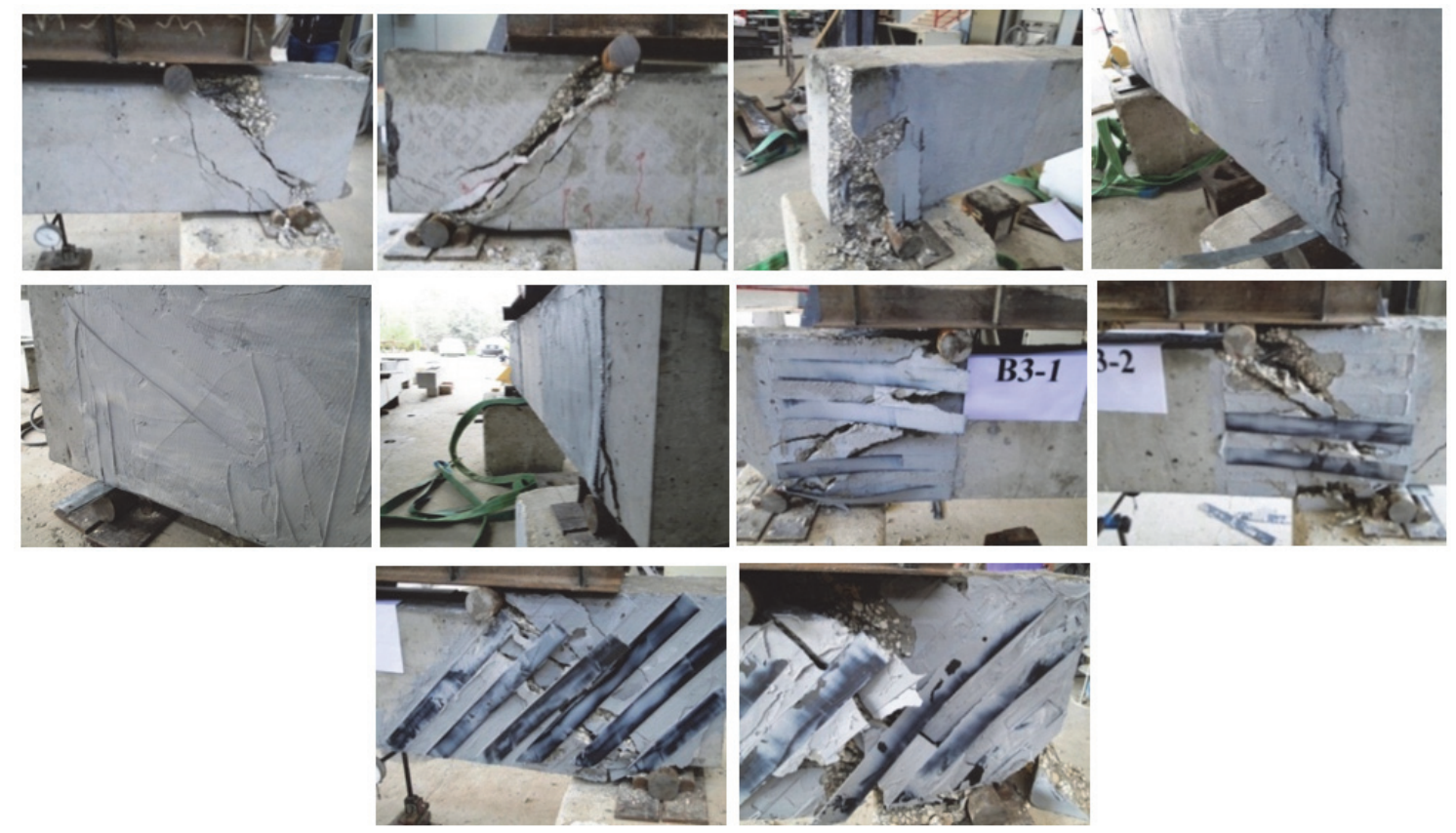

Figure 4. Failure modes of tested beams in Group (A). 


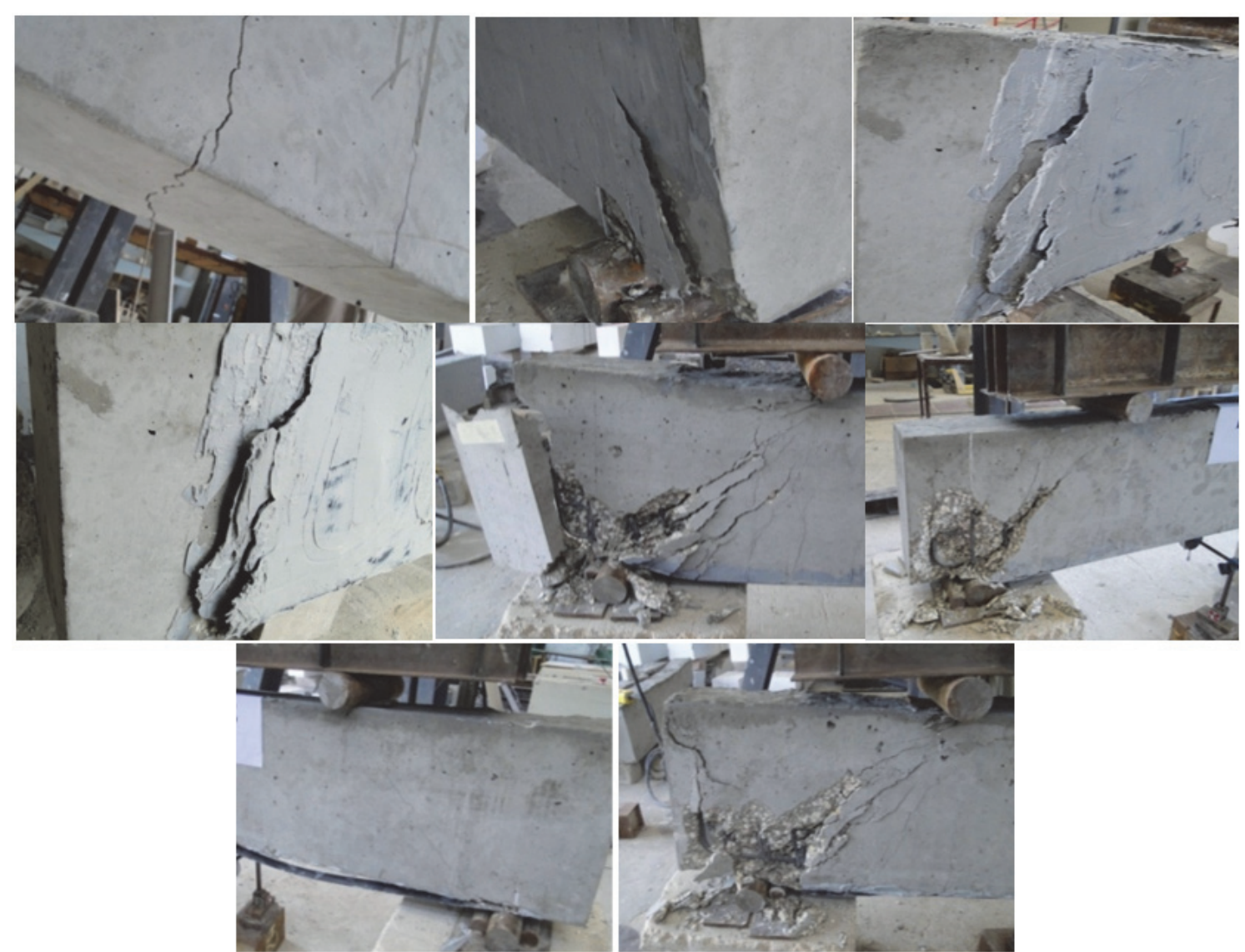

Figure 5. Failure modes of tested beams in Group (B)

\subsection{Ultimate Strength}

Table 3. A summary of the ultimate strength attained by each beam in Group (A) and Group (B)

\begin{tabular}{|c|c|c|c|c|c|c|}
\hline Group No. & $\begin{array}{l}\text { Beam } \\
\text { specimen }\end{array}$ & $\begin{array}{l}\text { CFRP } \\
\text { material }\end{array}$ & $\begin{array}{l}\text { Ultimate } \\
\text { load }(\mathrm{kN})\end{array}$ & $\begin{array}{l}\text { Increase in } \\
\text { ultimate load }(\%)\end{array}$ & $\begin{array}{l}\text { Average } \\
\text { increase (\%) }\end{array}$ & Mode of failure \\
\hline \multirow[t]{10}{*}{ Group(A) } & B-1(A) & - & 375 & - & - & shear failure \\
\hline & B-2(A) & & 376 & - & & shear failure \\
\hline & B1-1(A) & sheets & 653 & $73.9 \%$ & $79.5 \%$ & rupture of CFRP sheets \\
\hline & B1-2(A) & & 695 & $85.1 \%$ & & delamination of CFRP sheets \\
\hline & B2-1(A) & & no failure & - & - & no failure \\
\hline & B2-2(A) & & 592 & - & & the beam tilted \\
\hline & B3-1(A) & laminates & 410 & $9.2 \%$ & $10.2 \%$ & shear failure \\
\hline & B3-2(A) & & 417 & $11.1 \%$ & & shear failure \\
\hline & B4-1(A) & & 507 & $35.0 \%$ & $36.6 \%$ & shear failure \\
\hline & B4-2(A) & & 519 & $38.2 \%$ & & shear failure \\
\hline \multirow[t]{10}{*}{ Group(B) } & B-1(B) & - & 475 & - & - & flexural failure \\
\hline & B-2(B) & & 425 & - & & flexural failure \\
\hline & B1-1(B) & sheets & 600 & $33.3 \%$ & $27.4 \%$ & flexural failure \\
\hline & B1-2(B) & & 547 & $21.6 \%$ & & flexural failure \\
\hline & B2-1(B) & & 500 & - & $51.1 \%$ & the beam tilted \\
\hline & B2-2(B) & & 680 & $51.1 \%$ & & delamination of CFRP sheets \\
\hline & B3-1(B) & laminates & 567 & $26.0 \%$ & $26.0 \%$ & shear failure \\
\hline & B3-2(B) & & 500 & - & & the beam tilted \\
\hline & B4-1(B) & & 510 & $13.3 \%$ & $9.4 \%$ & shear failure \\
\hline & B4-2(B) & & 475 & $5.6 \%$ & & shear failure \\
\hline
\end{tabular}


Compared to the two control beams, all the beams strengthened either with CFRP sheets or laminates showed a significant increase in the ultimate strength. A further comparison between the four investigated schemes within Group (A) indicates that the beam strengthened by bonding the two layers of sheets, B2-1(A), exhibited the highest increase in the ultimate shear strength, exceeding a value of $86 \%$ over the control beams, whereas the two beams strengthened with one layer of sheets, B1-1(A) and B1-2(A), recorded a nearly similar increase with an average of $79.5 \%$. Alternatively, for the four beams strengthened with CFRP laminates, the two beams strengthened using the inclined laminates, B4-1(A) and B4-2(A), showed the highest increase in the ultimate strength reached to an average value of $36.6 \%$ over the control beams, whereas the two beams strengthened with the horizontal arrangement, B3-1 and B3-2, recorded an average increase only of $10.2 \%$. This confirms the better performance of the inclined arrangement of laminates when compared to the horizontal one due to the increase in resisting of diagonal shear cracks resulted from being the CFRP laminates nearly perpendicular to these cracks.

Similarly, for the four strengthened beams of Group (B), an enhancement of about $51.1 \%$ in the ultimate flexural strength was recorded for the beam strengthened with two layers of sheets over the entire beam, B2-2(B), while an average increase of about $27.4 \%$ was achieved by using the one layer of sheets for beam B2-1(B) and Beam B2-2(B). In contrast, for the four beams strengthened with CFRP laminates on the beams' soffit, covering the total width of beams B3-1(B) and B3-2(B) showed the highest increase in the ultimate strength with an average of $26 \%$, compered only to $9.4 \%$ when the laminates of $50 \mathrm{~mm}$ width were separated by a clear distance of 90 $\mathrm{mm}$, as in beam B4-1(B) and beam B4-2(B). This determines the effect of CFRP laminates' width on the ultimate resistance.

It should be mentioned here that due to the sudden tilt of beams B2-2(A), B2-1(B) and B3-2(B) during the test, it was decided to exclude the obtained results of these specimens in order to avoid any uncertainty in this work, particularly when the experimental results are analyzed.

\subsection{Load against Deflection Response}

In comparison to the control beams of Group (A), shear strengthening of RC deep beams either by CFRP sheets or laminates caused a noticeable increase in stiffness, particularly during the final stages of loading. The load against the mid-span deflection curves of the two control beams and the strengthened beams of Group (A) are plotted in Figure 6. Conversely, flexural strengthening of RC deep beams with CFRP materials increased the ductility of beams. This can be clearly shown through Figure 7 of the load versus the mid-span deflection curves of the beams in Group (B).

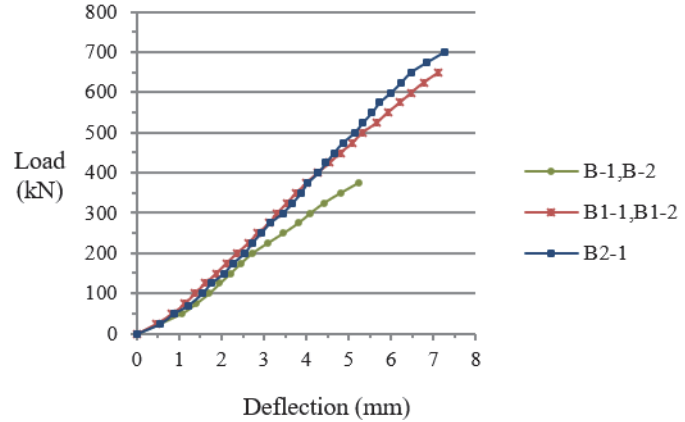

(a) curves of beams in group $I$ and group $I I$

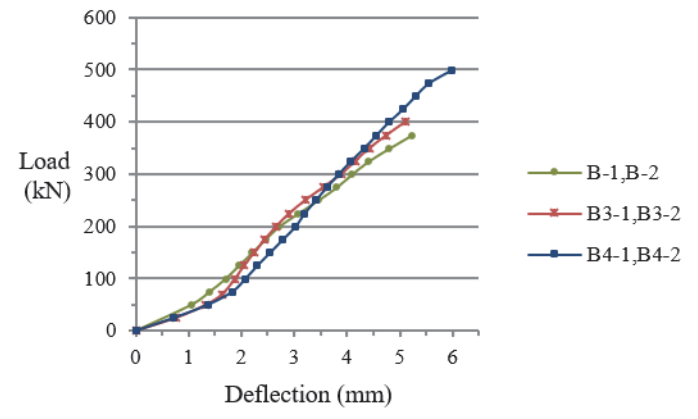

(b) curves of beams in group $I$ and group $I I I$

Figure 6. Load versus deflection curves of beams in Group (A).

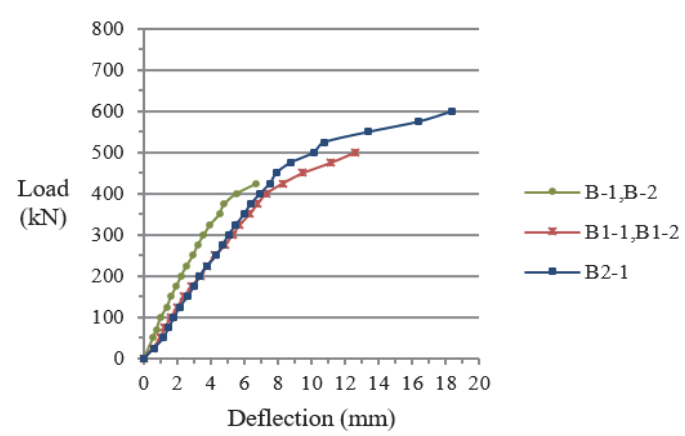

(a) curves of beams in group $I$ and group $I I$

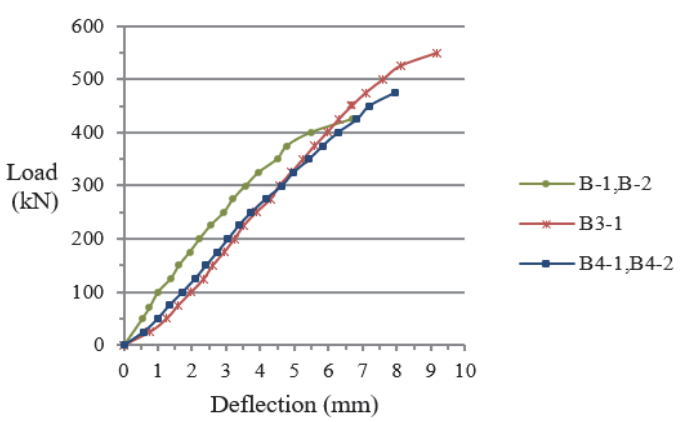

(b) curves of beams in group $I$ and group $I I I$

Figure 7. Load against deflection curves of beams in Group (B). 


\section{Conclusions}

From the obtained test results, that presented and discussed throughout this study, the following points could be concluded:

- The effectiveness of CFRP composites on enhancing both the shear and flexural capacity of deep beams is verified; however, the efficiency differs variedly depending on the material and the strengthening scheme.

- Although the use of CFRP sheets for shear strengthening is found to be the most useful and practical system concerning the amount of material consumed and the ultimate strength attained, the other system of using the laminates is found to be almost equally effective. However, taking the economic aspect into consideration resulted in adopting the use of CFRP sheets rather than laminates.

- Regarding the shear strengthening, using the continuous wrap of two sheets records the highest increase in the ultimate strength with a value exceeds $86 \%$ over the control beams, even though the beams strengthened by one layer of sheet showed a nearly similar increase reached to about $79 \%$ over the control beams. Thus, it can be concluded that the use of one layer of CFRP sheets is more efficient for practical solutions.

- Orientation of carbon fibers is found to be a major factor in the influence of CFRP materials on the shear resistance of strengthened beams. The CFRP laminates oriented at an angle of 450 with respect to the longitudinal axis of the beam are more effective than the horizontal ones in increasing the beam's ultimate strength. This can be verified as an increase of about $36 \%$ was recorded for the inclined laminates compared only to $10 \%$ when the horizontal laminates were used.

- The use of CFRP sheets is found to be more effective than using CFRP laminates in enhancing the flexural resistance of deep beams.

- Concerning the flexural strengthening, the maximum enhancement in the ultimate flexural strength was reached using the two layers of sheets with a value of $51 \%$ over the control beams, and thus it is determined as the best configuration for flexural strengthening, while an average increase of about $27 \%$ was recorded when the one layer was used.

- The effect of laminates' width on the contribution of CFRP material to the ultimate strength is confirmed; since a $26 \%$ rise in the ultimate strength was attained by distributing the laminates over the total width of the beam's soffit, compared only to $9 \%$ when the laminates' width was decreased.

- Flexural strengthening of deep beams by CFRP laminates changes the failure's pattern from flexure; which tends to be more ductile in nature, to shear. Taking the shear strengthening into consideration is; therefore, an important issue when the flexural strengthening is performed.

- The use of CFRP materials delayed the initial formation of critical shear and flexural cracks, and hence increasing the beams' total capacity. A major increase was observed in the load at which the initial cracks formed.

- Generally, shear strengthening of RC deep beams either with CFRP sheets or laminates leads to a substantial reduction in the formation as well as the development of critical shear cracks, enhances the ultimate strength and the overall stiffness; however, the ductility is improved in the case of flexural strengthening.

- Regarding the partial delamination of CFRP sheets near the supports, the use of mechanical anchorage system could eliminate this delamination, causing a greater increase of the ultimate strength; since the full capacity of the CFRP sheets could be utilized.

\section{Acknowledgments}

The financial support of the Deanship of Scientist Research and the technical support by the Civil Engineering Department at The University of Jordan is gratefully acknowledged.

\section{References}

Abdel-Jaber, M. S., Shatanawi, A. S., \& Abdel-Jaber, M. S. (2007). Guidelines for shear strengthening of beams using carbon fibre-reinforced polymer (FRP) plates. Jordan Journal of Civil Engineering, 1(4), 327-335.

Adhikary, B. B., \& Mutsuyoshi, H. (2004). Behavior of concrete beams strengthened in shear with carbon-fiber $\begin{array}{lllll}\text { sheets. Journal of Composites for } & \text { Construction, } & 8(3), & \text { 258-264. }\end{array}$ https://doi.org/10.1061/(ASCE)1090-0268(2004)8:3(258)

Al-Amery, R., \& Al-Mahaidi, R. (2006). Coupled flexural-shear retrofitting of RC beams using CFRP straps. Composite Structures, 75, 457-464. https://doi.org/10.1016/j.compstruct.2006.04.037 
Al-Tersawy, S. H. (2013). Effect of fiber parameters and concrete strength on shear behavior of strengthened RC $\begin{array}{lllll}\text { beams. Construction } & \text { Building }\end{array}$ https://dx.doi.org/10.1016/j.conbuildmat.2013.03.007

American Concrete Institute: ACI Committee 318. (2014). Building Code Requirements for Structural Concrete (ACI 318M-14) and Commentary (318RM-14). Michigan: Farmington Hills.

Attari, N., Amziane, S., \& Chemrouk, M. (2012). Flexural strengthening of concrete beams using CFRP, GFRP and hybrid FRP sheets. Construction and Building Materials, 37, 746-757. https://dx.doi.org/10.1016/j.conbuildmat.2012.07.052

Baggio, D., Soudki, K., \& Noël, M. (2014). Strengthening of shear critical RC beams with various FRP systems. Construction and Building Materials, 66, 634-644. https://dx.doi.org/10.1016/j.conbuildmat.2014.05.097

Belarbi, A., \& Acun, B. (2013). FRP systems in shear strengthening of reinforced concrete structures. Proceedings of $11^{\text {th }}$ International Conference on Modern Building Materials, Procedia Engineering, 57, 2-8. https://doi.org/10.1016/j.proeng.2013.04.004

Bousselham, A., \& Chaallal, O. (2006). Behaviour of reinforced concrete T-beams strengthened in shear with carbon reinforced polymer-an experimental study. ACI Structural Journal, 103(3), 339-347.

Ceroni, F. (2010). Experimental performances of RC beams strengthened with FRP materials. Construction and Building Materials, 24, 1547-1559. https://dx.doi.org/10.1016/j.conbuildmat.2010.03.008

Esfahania, M., Kianoushb, M., \& Tajaria, A. (2007). Flexural behaviour of reinforced concrete beams $\begin{array}{lllll}\text { strengthened by CFRP sheets. Engineering Structures, 29, 2428-2444. } & \text {. }\end{array}$ https://doi.org/10.1016/j.engstruct.2006.12.008

Godat, A., \& Chaallal, O. (2013). Strut-and-tie method for externally bonded FRP shear-strengthened large-scale RC beams. Composites Structures, 99, 327-338. https://dx.doi.org/10.1016/j.compstruct.2012.11.034

Hsu, C., Punurai, W., Bian, H., \& Jai, Y. (2003). Flexural strengthening of reinforced concrete beams using carbon fiber reinforce polymer strips. Magazine of Concrete Research, 55(3), 279-288.

Islam, M. R., Mansur, M. A., \& Maalej, M. (2005). Shear strengthening of RC deep beams using externally bonded FRP systems. Journal of Cement Concrete Composites, 27(3), 413-420. https://doi.org/10.1016/j.cemconcomp.2004.04.002

Jayaprakash, J., Abdul Samad, A. A., Abbasovich, A. A., \& Ali, A. A. (2008). Shear capacity of percracked and non-percracked reinforced concrete shear beams with externally bonded bi-directional CFRP strips. Construction and Building Materials, 22. https://doi.org/10.1016/j.conbuildmat.2007.02.008

Khalifa, A., \&Nanni, A. (2002). Rehabilitation of rectangular simply supported RC beams with shear deficiencies using CFRP composites. Construction and Building Materials, 16(3), 135-146. https://doi.org/10.1016/S0950-0618(02)00002-8

Lamanna, A., Bank, L., \& Scott, D. (2004). Flexural strengthening of reinforced concrete beams by mechanically attaching fiber-reinforced polymer strips. Journal of Composites for Construction, 8(3), 203-210. https://doi.org/10.1061/(ASCE)1090-0268(2004)8:3(203)

Lee, H. K., Cheong, S. H., Ha, S. K., \& Lee, C. G. (2011). Behavior and performance of RC T-section deep beams externally strengthened in shear with CFRP sheets. Composite Structures, 93, 911-922. http://doi.org/10.1016/j.compstruct.2010.07.002

Mofidi, A., \& Challal, O. (2011). Shear strengthening of RC beams with EB FRP composites: effect of strip-width to strip-spacing ratio. Journal of Composites for Construction, 15(5), 732-742. http://doi.org/10.1061/(ASCE)CC.1943-5614.0000219

National Cooperative Highway Research Program: NCHRP Report 678 (2011). Design of FRP Systems for Strengthening Concrete Girders in Shear, Transportation Research Board, Washington DC, USA.

Nawy. E. G. (2009). Reinforced Concrete: A Fundamental Approach, ACI 318-08 Code (6 ${ }^{\text {th }}$ ed.). Upper Saddle River, NJ: Prentice Hall.

Park, S., \& Abouatah, R. (2009). Strut-and-tie method for CFRP strengthened deep RC members. J. Struct. Eng., 135 (6), 632-643. http://doi.org/10.1061/(ASCE)0733-9445(2009)135:6(632)

Siddiqui, N. (2009). Experimental investigation of RC beams strengthened with externally bonded FRP composites. Latin American Journal of Solids and Structures, 6(4), 343-362. 
Sobuz, H., Ahmed, E., Hasan, N. \& Uddin, A. (2011). Use of carbon fiber laminates for strengthening reinforced concrete beams in bending. International Journal of Civil and Structural Engineering, 2(1), 67-84.

Wight, J. K., \& MacGregor, J. G. (2012). Reinforced Concrete: Mechanics and Design ( $6^{\text {th }}$ ed.), Upper Saddle River, NJ: Prentice Hall.

Yang, K. H., Chung, H. S., Lee, E. T., \& Eun, H.C. (2003). Shear characteristics of high-strength concrete deep beams without shear reinforcements. Engineering Structures, 25, 1343-1352. https://doi.org/10.1016/S0141-0296(03)00110-X

Zhang, Z., Hsu, C. T., \& Moren, J. (2004). Shear strengthening of reinforced concrete deep beams using carbon fiber reinforced polymer laminates. ASCE Journal of Composites for Construction, 8(5), 403-414. https://doi.org/10.1061/(ASCE)1090-0268(2004)8:5(403)

\section{Copyrights}

Copyright for this article is retained by the author(s), with first publication rights granted to the journal.

This is an open-access article distributed under the terms and conditions of the Creative Commons Attribution license (http://creativecommons.org/licenses/by/4.0/). 